\title{
A NEW WAY TO VISUALLY REPRESENT DOMINANCE IN ECOLOGICAL COMMUNITIES
}

\author{
Raul Ortiz-Pulido ${ }^{1}$ Edgar Chávez-González ${ }^{1}$, and Roger Guevara ${ }^{2}$ \\ ${ }^{1}$ Universidad Autonoma del Estado de Hidalgo \\ ${ }^{2}$ Instituto de Ecologia A.C.
}

May 5, 2020

\begin{abstract}
Abstract: Dominance hierarchies have been visually represented in several ways, but most leave it difficult to quickly understand complex interactions between multiple entities in a community. Here we propose a new way to visually represent the hierarchy of dominance between entities in such systems called an "agonistic diagram". We demonstrate this method using data from nectar-feeding bird communities in Australia and America, then using data from inquiline ants, European Badgers, and urban cats. The advantages of using agonistic diagrams are: (1) that the agonistic diagram can be compared visually with other interaction diagrams in related fields, like mutualism, and (2) that the analytical tools used in other fields can be used to assess agonistic networks. Thus, agonistic networks can be quantified in new ways, making it possible to obtain with relatively minor changes, automated agonistic diagrams from the computational programs and ecological metrics that are currently used to understand mutualistic interactions. This includes metrics of nestedness, modularity, and robustness, the identity of core and peripheral species, and the effects of extinction on networks, among other information.
\end{abstract}

Authorship: RO-P conceived the ideas for the paper and collected the data; RO-P and EC-G conducted the analysis; EC-G and RG develop the computational program; RO-P wrote the manuscript; all the authors discussed the results and commented on the manuscript.

Data accessibility statement: If the manuscript is accepted, the data supporting the results will be archived in an appropriate public repository (Dryad) and the data DOI will be included at the end of the article. There are some supporting data already published, in all the cases appropriate citation is provided in text.

\section{Hosted file}

LC_Text_v7_without_authors.docx available at https://authorea.com/users/294283/articles/ 428790-a-new-way-to-visually-represent-dominance-in-ecological-communities

\section{Hosted file}

LC_Figure_1_new_v7.docx available at https ://authorea.com/users/294283/articles/428790-a-newway-to-visually-represent-dominance-in-ecological-communities

\section{Hosted file}

LC_Figure_2_v7.docx available at https://authorea.com/users/294283/articles/428790-a-newway-to-visually-represent-dominance-in-ecological-communities

\section{Hosted file}


LC_Figure_3_v7.docx available at https://authorea.com/users/294283/articles/428790-a-newway-to-visually-represent-dominance-in-ecological-communities 